\title{
Association Analysis Between Different Diabetic Family History and Gender with Diagnosed Age of Type 2 Diabetes Mellitus: A Cross-sectional Study in Tianjin, China
}

\section{Zhaohu Hao ( $\sim$ keddyhm@163.com )}

Tianjin 4th Central Hospital https://orcid.org/0000-0002-3965-3805

\section{Xiao Huang}

Tianjin Medical University

Xiaohui Liu

Tianjin 4th Central hospital

Rong Xu

Tianjin 4th Central Hospital

JunXin Yao

Tianjin 4th Central Hospital

Feng He

Tianjin 4th Central Hospital

Hailin Shao

Tianjin 4th Central Hospital

\section{Research}

Keywords: type 2 diabetes mellitus, early onset type 2 diabetes mellitus, diabetic family history, gender

Posted Date: December 16th, 2020

DOl: https://doi.org/10.21203/rs.3.rs-126128/v1

License: (c) (1) This work is licensed under a Creative Commons Attribution 4.0 International License. Read Full License

Version of Record: A version of this preprint was published at INQUIRY: The Journal of Health Care Organization, Provision, and Financing on January 1st, 2022. See the published version at https://doi.org/10.1177/00469580221086364. 


\section{Abstract}

Background: To investigate the correlation between different diabetic family history and gender with diagnosed age of type 2 diabetes mellitus(T2DM).

Methods: To register the newly diagnosed T2DM patients who were admitted to the diabetes identification center of our hospital from October 2017 to June 2020. According to whether the age of diagnosis is more than 40 years old, patients were divided into two groups (early-onset T2DM and lateonset T2DM). In the study,the DM family history was divided into five types: (a)Father DM:Only the father had diabetes in both parents;(b)Mother DM:Only the mother had diabetes in both parents;(c)Both parents DM,Both parents have DM;(d)other family history of DM (without father or mother with DM) and (e)without family history of DM.The diagnosed age with different genders and diabetic family history is compared.Multivariate logistic regression analysis was used to investigate the correlation factors of early-onset T2DM.

Results: 3725 patients completed the survey. There were 589 patients (15.8\%) with early-onset T2DM, and2469 patients $(66.3 \%)$ had diabetic family history. The T2DM diagnosed age in male was lower than that in female $(51.7 \pm 11.2 v s 54.0 \pm 10.2, t=-6.283, p<0.001)$. The result was also reflected in different $D M$ family history (with Both parents $D M, 46.7 \pm 11.1 v s 48.5 \pm 10.3, t=-1.105, p=0.271$; with Father $\mathrm{DM}, 46.8 \pm 10.8 \mathrm{vs} 49.8 \pm 11.3, \mathrm{t}=-2.825, \mathrm{p}=0.005$; with Mother $\mathrm{DM}, 50.4 \pm 10.6 \mathrm{vs52.3} \pm 10.2, \mathrm{t}=-2.342, \mathrm{p}=0.019$; with other DM familiy history, $54.0 \pm 10.8 \mathrm{vs} 55.7 \pm 9.5, \mathrm{t}=-2.652, \mathrm{p}=0.008$; with NO DM familiy history, $53.0 \pm 11.0 v s 55.9 \pm 9.3, t=-4.738, p<0.001)$.T2DM diagnosed age with both parents $\mathrm{DM}(47.5 \pm 11.0)$ and father $\mathrm{DM}(47.9 \pm 11.1)$ family history<that with mother DM family history $(51.1 \pm 10.5)<$ that with other DM family history $(54.7 \pm 10.3)$ and no DM family history(54.1 \pm 10.5$)$. Logistic regression analysis indicated that gender(OR2.124,p<0.001), father DM history(OR2.7, $p<0.001)$, mother DM history(OR1.548,p=0.001), both parents $\mathrm{DM}(\mathrm{OR} 2.844, \mathrm{p}<0.001), \mathrm{BMI}(\mathrm{OR} 1.106, \mathrm{p}<0.001)$ and drinking history $(\mathrm{OR} 0.682, \mathrm{p}=0.002)$ were correlated with early-onset T2DM.

Conclusion: Patients with early-onset T2DM tend to have more obvious DM family history in China. This survey shows that the parent DM family history especially father diabetes family history, male patients are diagnosed T2DM earlier.Drinking history was negatively correlated with the early-onset T2DM in male patients.We need more aggressive screening for diabetes in children with a family history of diabetes, especially in men.

\section{Introduction}

Diabetes mellitus(DM) has become an important public health problem ${ }^{[1]}$.In 2017, China had 114.4 million people with DM, ranking first in the world ${ }^{[2]}$. DM was previously considered to be a common disease in middle-aged and elderly people, but the researches found that the age of diagnosis of DM is advancing year by year, and the trend of younger age is obvious ${ }^{[3]}$. According to the Epidemiological survey in China, the prevalence of pre-diabetes in people younger than 40 years old in 2013 was 
significantly higher than that in 2010 (28.8\% vs 9.0\%), and the prevalence of type 2 diabetes mellitus(T2DM) in people younger than 40 years old was $3.2 \%$ in 2010 , rising to $5.8 \%$ in $2013^{[4]}$. Between 1990 and 2000, T2DM in New York children increased tenfold ${ }^{[5]}$.The survey shows that T2DM has also increased significantly in British adolescents ${ }^{[6]}$. In 2003, the proportion of patients diagnosed with diabetes under the age of 30 accounted for $5 \%$ of the total population, and increased to $12 \%$ in $2006^{[6]}$, and the proportion of T2DM patients diagnosed $\leq 40$ years reached $24 \%\left[{ }^{[6]}\right.$.

Compared with the late-onset group, adolescents with DM have longer exposure time to hyperglycemia, higher risk of DM related complications and higher risk of cardiovascular disease ${ }^{[7]}$. The occurrence of T2DM in young people was first reported among American Indians ${ }^{[8]}$. Compared with late onset T2DM, the function of $\beta$-cell is worse in young people with $\mathrm{T}_{2} \mathrm{DM}^{[9]}$, and the young T2DM patients have a greater risk of complications ${ }^{[1]}$.T2DM in young people increases all-cause mortality, CVD mortality, stroke and ischemic heart disease mortality ${ }^{[10]}$, especially in men ${ }^{[11]}$.An Australian study showed that the risk of death from T2DM diagnosed at age 15 to 30 was three times higher than in the general population ${ }^{[12]}$. In contrast, for late onset T2DM, the risk of death gradually declines until the age of diagnosis is greater than 69 years old, which is comparable to the death rate of the general population ${ }^{[12]}$.Studies have shown that if young people develop T2DM, their life expectancy is reduced by 12 years ${ }^{[13]}$.After adjusting for age and sex, the risk of myocardial infarction in young patients with T2DM increased by 14 times, but that of late onset T2DM was only 4 times $^{[14]}$.In diabetic nephropathy(DN), diabetic retinopathy(DR) and peripheral neuropathy, the incidence rate of T2DM in young people is higher than that in T1DM ${ }^{[15]} \cdot \ln$ the observation of newly diagnosed T2DM patients, the age of onset of diabetes mellitus is significantly correlated with the occurrence of DR, and the screening rate of DR in patients with onset age $>60$ years old is significantly lower(OR $=0.289, p=0.009)^{[16]}$.

At present, T2DM is usually divided into early-onset T2DM and late-onset T2DM according to the onset age of 40 years old ${ }^{[3]} .60 \%$ of early-onset T2DM had one of their parents with diabetes, and $30 \%$ had one of their grandparents with diabetes ${ }^{[1]}$.After adjusting for age, gender and race, the risk ratio for T2DM in adolescents exposed to maternal diabetes was 5.7 , and that for maternal obesity was 2.8 , compared with non-diabetic control groups ${ }^{[17]}$.Early onset T2DM is a clinical syndrome caused by genetic and environmental factors, but its etiology and pathogenesis have not been fully elucidated.In the studies on the correlation between gender and early onset T2DM, the current conclusions are inconsistent ${ }^{[18]}$.According to the current situation of adult diabetes, many studies ${ }^{[19]}$ and Chinese studies $^{[20]}$ have shown that the prevalence of T2DM in men is higher than that in women.T2DM patients have obvious family genetic background.Is there any correlation between father's diabetes mellitus, mother's diabetes and other family history with the onset age of diabetic patients in Chinese people? There are few studies. Due to the insidious onset of T2DM, the exact age of onset is not easy to determine.In this study, we investigated newly diagnosed T2DM patients in our hospital to explore the correlation between different family history of diabetes, gender and the diagnosed age of T2DM. 


\section{Patients And Methods}

The present study was a single-centre cross-sectional study in Tianjin 4th Central Hospital. The hospital is a regional medical centre in Tianjin. The hospital had a diabetes identification centre. The patients in the region are identified by the department before they can enjoy more preferential health insurance policies in the clinic. The Metabolic Disease Management Center (MMC) was responsible for the screening for complications in patients with newly diagnosed diabetes in the hospital, such as urinary protein, fundus examination, peripheral vascular and neuropathy. The diabetes nursing team undertook the measurement of height, weight and blood pressure, and gathered information about smoking, drinking , disease history and family history of DM. Electronic medical records were generated at the same time.Only one patient could be enrolled in the same family.

Study participants were patients with newly diagnosed T2DM who visited MMC from October 2017 to June 2020. The patient information came from an electronic database of the hospital's diabetes identification centre. The clinical study protocol was approved by the Institutional Review Board (IRB)of Tianjin 4th Central Hospital, and all steps were conducted in accordance with the principles of the World Medical Association Declaration of Helsinki (trial registration code: ChiCTR2000036881). The IRB approved the collection and use of patients' records according to regulations for clinical trials in humans (IRB approval no.2019-SZXLL068). Written informed consent was obtained from each patient.

\section{Inclusion criteria:}

(a)The study enrolled participants with a baseline of being newly diagnosed with T2DM within the past 3 months; (b) age $\geq 18$ years; (c) patients without mental disorders who can communicate independently; (d)Patients can accurately describe their family history of diabetes, if the description is not clear, the parents can cooperate with MMC for OGTT examination.According to the Chinese guidelines for the prevention and treatment of diabetes, all patients with diabetes in our hospital are required to be diagnosed with an oral glucose tolerance test. The diagnostic criteria during the execution were as follows: (1) fasting plasma glucose $\geq 7.0 \mathrm{mmol} / \mathrm{L}$. Fasting was defined as no caloric intake for at least 8 hours; or (2) 2-hour plasma glucose $\geq 11.1 \mathrm{mmol} / \mathrm{L}$ during an oral glucose tolerance test(OGTT). The test was performed as described by the WHO, using a glucose load containing the equivalent of $75 \mathrm{~g}$ anhydrous glucose dissolved in water. A haemoglobin A1c ( $\mathrm{HbA1c}$ ) test was not standardised in China, so it could not be used as a diagnostic standard ${ }^{[21]}$.

\section{The exclusion criteria}

(a) type 1 and other special types of diabetes, gestational diabetes or diabetes mellitus with pregnancy; (b)patients with severe mental illness and unclear consciousness; (c) patients with active tuberculosis and other infectious diseases. 
Information about the patients' names, sex, phone numbers, body mass index (BMI), age, smoking history, drinking history, family history of DM, hypertension and HbA1c was collected using a uniform information table. The formula for BMI was weight in kilograms divided by the square of height in metres. Weight was measured using the same scale on an empty stomach at the MMC clinic in the morning and recorded.BMI ( $\geq 28 \mathrm{~kg} / \mathrm{m}^{2}$ ) met obesity criteria according to Chinese standards ${ }^{[22]}$.Smoking status assessment: according to the WHO (1997) smoking survey method, smoking at least one cigarette per day for $>6$ months was considered as a smoking history ${ }^{[23]}$.Venous blood samples were collected in EDTA tubes from fasting patients in the morning. The level of $\mathrm{HbA1c}$ was determined by affinity chromatography in the hospital standard laboratory (Tosoh Corporation, Japan). All patient identifiers were removed prior to analysis.

\section{Evaluation of clinical variables:}

In this study, the identification methods of parents' DM in family history were as follows: 1) previous diagnosis; 2) no definite diagnosis was confirmed by OGTT. In this study, the incidence of diabetes in family members other than parents mainly depends on the description of the patients.(1)Classification of family history of T2DM: In the study,according to the prevalence of diabetes in parents and other relatives, the family history of T2DM can be divided into five types(Fig. 1): (a)Father DM:Only the father had diabetes in both parents;(b)Mother DM:Only the mother had diabetes in both parents;(c)Both parents DM,Both parents have DM; (d)other family history of DM (without father or mother with DM) and (e)without family history of DM. Other family histories of diabetes include grandparents, maternal grandparents, siblings and children.(2)Diagnostic age of early onset T2DM:The demarcation line between early onset and late onset T2DM is not completely consistent.In recent years, a number of large-scale studies in Asia, such as JADE project group, defined early-onset T2DM as the diagnosis age $<40$ years old in the study of "metabolic profile and treatment gap of Asian youth with type 2 diabetes" ${ }^{[3]}$.A study in China on cardiovascular disease risk of early-onset T2DM also takes the age of 40 as the boundary ${ }^{[24]}$.In the present study, early-onset T2DM was defined as age $<40$ years old at the time of diagnosis, and lateonset T2DM was defined as $\geq 40$ years old.

\section{Observation indexes:}

the main observation indices included: (a)Diagnosis age of T2DM patients with different family history; (b)Age of diagnosis in male and female T2DM patients;(c) The correlation between different family history of T2DM, gender and age at diagnosis of T2DM.Secondary outcome measures included:The correlation between early-onset type 2 diabetes and gender, family history of diabetes.

\section{Statistical analysis:}


SPSS 20.0 statistical software package(IBM Corp. Released 2011. IBM SPSS Statistics for Windows, Version 20.0. Armonk, NY: IBM Corp.) was used for data collation and analysis. Descriptive analysis was used to illustrate the basic demographic characteristics. For continuous variables, a onesample Kolmogorov-Smirnov normality test was used to check the normality of the distribution of such variables. Mean \pm standard deviation was used for statistical description of variables conforming to normal distribution, median (P50) was used for those not conforming to normal distribution, and percentage (\%) was used for counting data. When comparing the age at diagnosis of patients with different family history and gender of diabetes, one-way anova was first adopted and further comparison between groups was conducted using Student-Newman-Keuls test(SNK test).To analyse the factors associated with earlyonset T2DM and adjust for potential confounding effects, we examined the factors using multivariable logistic regression analysis.All statistical tests were performed by bilateral test with alpha $=0.05$.

\section{Patient and public involvement}

Patients were not involved in setting the research questions or planning the study. Investigators did not know the identities of the study participants. In this study, the electronic data were obtained from the health records at the institution. All patient identifiers were removed before the analysis was conducted. There was no direct patient or public involvement.

\section{Results}

\section{Demographic and clinical characteristics of the study population}

A total of 3725 patients with T2DM participated and completed the survey, all of them were Han nationality. Their average age was $52.6 \pm 10.8$ years. The systolic blood pressure(SBP) was $142.4 \pm$ $20.1 \mathrm{mmhg}$, diastolic blood pressure(DBP) was $81.7 \pm 11.4 \mathrm{mmhg}$, waist circumference(WC) was $96.2 \pm$ $10.7 \mathrm{~cm}$, body weight was $76.1 \pm 13.7 \mathrm{~kg}$, BMl was $27.3 \pm 4.0 \mathrm{~kg} / \mathrm{m}^{2}$. Fasting peripheral blood glucose(FBP) was $8.98 \pm 2.76 \mathrm{mmol} / \mathrm{l}$, 2-hour postprandial blood glucose(P2BG) was $17.58 \pm$ $4.41 \mathrm{mmol} / \mathrm{l}$ and $\mathrm{HbA} 1 \mathrm{c}$ was $8.73 \pm 1.81 \%$. Baseline characteristics are shown in Table 1. 
Table 1

Baseline characteristics of the study participants

\begin{tabular}{|lll|}
\hline Items & N(3725) & $\%$ \\
\hline Sex & & \\
\hline male & 2288 & 61.4 \\
\hline female & 1437 & 38.6 \\
\hline With smoking history & 1670 & 44.8 \\
\hline With drinking history & 846 & 22.7 \\
\hline With hypertension & 2025 & 54.4 \\
\hline With coronary heart disease history & 785 & 21.1 \\
\hline With cerebral infarction history & 411 & 11.0 \\
\hline With family history of DM & 2469 & 66.3 \\
\hline Father DM & 453 & 12.2 \\
\hline Mother DM & 696 & 18.7 \\
\hline Both parents DM & 190 & 5.1 \\
\hline Other DM family history & 1130 & 30.3 \\
\hline $\begin{array}{l}\text { Note:DM, diabetes mellitus; Father DM,Only the father had diabetes in both parents;Mother DM,Only } \\
\text { the mother had diabetes in both parents;Both parents DM,Both parents have DM. }\end{array}$ \\
\hline
\end{tabular}

\section{Age of T2DM diagnosis with different DM family history and gender}

The age comparison of patients with different family history of DM was shown in Table 2. The $F$ value of analysis of variance was $54.382, \mathrm{P}<0.001$. SNK test showed that patients with a family history of diabetes in both father and parents were diagnosed at the earliest age,the age of diagnosis was second only in those with mother $D M, P<0.05$. The age at diagnosis of T2DM was $51.7 \pm 11.2$ years for male and $54.0 \pm 10.2$ for female. The age of male was lower than that of female $(t=-6.283, P<0.001)$. 
Table 2

T2DM diagnosed age comparison of patients with different types of family history

\begin{tabular}{|llllll|}
\hline & $\begin{array}{l}\text { Both parents } \\
\text { DM }\end{array}$ & $\begin{array}{l}\text { Father } \\
\text { DM }\end{array}$ & $\begin{array}{l}\text { Mother } \\
\text { DM }\end{array}$ & $\begin{array}{l}\text { Other DM family } \\
\text { history }\end{array}$ & $\begin{array}{l}\text { No DM family } \\
\text { history }\end{array}$ \\
\hline N & 190 & 453 & 696 & 1130 & 1256 \\
\hline $\begin{array}{l}\text { Diagnosed } \\
\text { age }\end{array}$ & $47.5 \pm 11.0^{\mathrm{a}}$ & $\begin{array}{l}47.9 \pm \\
11.1^{\mathrm{a}}\end{array}$ & $\begin{array}{l}51.1 \pm \\
10.5^{\mathrm{b}}\end{array}$ & $54.7 \pm 10.3^{\mathrm{C}}$ & $54.1 \pm 10.5^{\mathrm{C}}$ \\
\hline \multicolumn{7}{|l|}{$\begin{array}{l}\text { Note: a, b and c indicate that there is a statistical difference between different labels by SNK test, but } \\
\text { there is no statistical difference in the same label, } \mathrm{p}<\text { 0.05;Father DM:Only the father had diabetes in } \\
\text { both parents;Mother DM:Only the mother had diabetes in both parents;Both parents DM,Both parents } \\
\text { have DM;Other DM family history:with DM family history(without father or mother with T2DM). }\end{array}$} \\
\hline
\end{tabular}

In patients with different types of DM family history, we compared the T2DM diagnosed age in different genders. Among the patients with Father $\mathrm{DM} \square \mathrm{M}$ other DM $\square$ Other DM family history and patients without DM family history, the diagnosed age in male patients was less than that in women, $p<0.05$, in Table 3 .

Table 3

Comparison of diagnosed age with different family history in different genders

\begin{tabular}{|c|c|c|c|c|c|c|}
\hline SEX & & $\begin{array}{l}\text { Both } \\
\text { parents DM }\end{array}$ & $\begin{array}{l}\text { Father } \\
\text { DM }\end{array}$ & $\begin{array}{l}\text { Mother } \\
\text { DM }\end{array}$ & $\begin{array}{l}\text { Other DM family } \\
\text { history }\end{array}$ & $\begin{array}{l}\text { No DM family } \\
\text { history }\end{array}$ \\
\hline \multirow[t]{2}{*}{ male } & $\mathrm{N}$ & 108 & 286 & 425 & 656 & 813 \\
\hline & $\begin{array}{l}\text { Diagnosed } \\
\text { age }\end{array}$ & $46.7 \pm 11.1^{\mathrm{a}}$ & $\begin{array}{l}46.8 \pm \\
10.8^{a}\end{array}$ & $\begin{array}{l}50.4 \pm \\
10.6^{\mathrm{b}}\end{array}$ & $54.0 \pm 10.8^{c}$ & $53.0 \pm 11.0^{c}$ \\
\hline \multirow[t]{2}{*}{ female } & $N$ & 82 & 167 & 271 & 474 & 443 \\
\hline & $\begin{array}{l}\text { Diagnosed } \\
\text { age }\end{array}$ & $48.5 \pm 10.3^{1}$ & $\begin{array}{l}49.8^{ \pm} \\
11.3^{1}\end{array}$ & $\begin{array}{l}52.3 \pm \\
10.2^{2}\end{array}$ & $55.7 \pm 9.5^{3}$ & $55.9 \pm 9.3^{3}$ \\
\hline \multicolumn{2}{|l|}{ t value } & -1.105 & -2.825 & -2.342 & -2.652 & -4.738 \\
\hline \multicolumn{2}{|l|}{$\begin{array}{l}\mathrm{p} \\
\text { value }\end{array}$} & 0.271 & 0.005 & 0.019 & 0.008 & $<0.001$ \\
\hline \multicolumn{7}{|c|}{$\begin{array}{l}\text { Note: }(a, b, c) \text { and }(1,2,3) \text { indicate that there is a statistical difference between different labels by SNK } \\
\text { test, but there is no statistical difference in the same label, } p<0.05 \text {.Father DM:Only the father had } \\
\text { diabetes in both parents;Mother DM:Only the mother had diabetes in both parents;Both parents } \\
\text { DM,Both parents have DM;Other DM family history:with DM family history(without father or mother } \\
\text { with T2DM). }\end{array}$} \\
\hline
\end{tabular}

The average diagnosed age of male patients in different types family history was compared between groups $(F=32.375, P<0.001)$, and that in female patients was compared $(F=671, P<0.001)$. T2DM diagnosed age with both parents DM and father DM family history < that with mother DM family history < that with other types of DM family history and no DM family history in Table 3(SNK test, $p<0.05$ ). 


\section{Univariate comparison between early onset T2DM and non- early onset T2DM patients}

In the present study, 589 patients (15.8\%) with early-onset T2DM were used as the observation group and 3136 patients (84.2\%) with non-early-onset T2DM were used as the control group. The univariate differences in gender, smoking history, smoking history, family history of DM, BMI and waist circumference $(\mathrm{WC})$ were compared, as shown in Table 4. There were statistically significant differences in gender composition, $\mathrm{BMI}, \mathrm{WC}$, family history of $\mathrm{DM}$, and $\mathrm{HbA1}$ c between the two groups $(\mathrm{p}<0.05)$.

Table 4

univariate comparison between the two groups

\begin{tabular}{|lllll|}
\hline Items & early onset T2DM & non-early onset T2DM & $\chi^{2} /$ t value & p value \\
\hline Sex $($ male $)$ & $415(70.5 \%)$ & $1873(59.7 \%)$ & 24.106 & $<0.001$ \\
\hline BMI $\left(\mathrm{kg} / \mathrm{m}^{2}\right)$ & $28.8 \pm 5.2$ & $27.0 \pm 3.7$ & $9.937^{*}$ & $<0.001$ \\
\hline Smoking history & $269(45.7 \%)$ & $1401(44.7 \%)$ & 0.199 & 0.656 \\
\hline Drinking history & $113(19.2 \%)$ & $733(23.4 \%)$ & 4.956 & 0.026 \\
\hline DM family history & $429(72.8 \%)$ & $2040(65.1 \%)$ & 13.445 & $<0.001$ \\
\hline WC $(\mathrm{cm})$ & $98.8 \pm 12.9$ & $95.8 \pm 10.2$ & $6.207^{*}$ & $<0.001$ \\
\hline HbA1c(\%) & $9.26 \pm 1.89$ & $8.63 \pm 1.78$ & $7.413^{*}$ & $<0.001$ \\
\hline $\begin{array}{l}\text { Note: }{ }^{*} \text {, independent sample t test, the remainder is } \chi^{2} \text { test;BMl,body mass index;WC,Waist } \\
\text { circumference. }\end{array}$ & & & \\
\hline
\end{tabular}

\section{Logistic regression analysis on related factors of early onset T2DM}

Taking early-onset T2DM as dependent variable, family history of diabetes, gender, smoking history, drinking history and BMI as independent variables, multiple logistic regression analysis was used to analyse the related factors of early onset T2DM in Table 5.Gender, father DM history, mother DM history, both parents $\mathrm{DM}$,drinking history and BMI were all correlated with early-onset T2DM, and drinking history was negatively correlated. 
Table 5

Logistic regression analysis on related factors of early onset T2DM

\begin{tabular}{|llllll|}
\hline Items & $\boldsymbol{\beta}$ & Wald $\mathbf{\chi}^{2}$ & $\mathbf{P}$ & OR & $\mathbf{9 5 \%} \mathrm{Cl}$ \\
\hline BMI & 0.100 & 84.472 & $<0.001$ & 1.106 & $1.082-1.129$ \\
\hline Gender & 0.753 & 39.226 & $<0.001$ & 2.124 & $1.678-2.688$ \\
\hline Smoking history & -0.155 & 1.896 & 0.168 & 0.856 & $0.686-1.068$ \\
\hline Drinking history & -0.383 & 9.264 & 0.002 & 0.682 & $0533-0.872$ \\
\hline DM family history & & 94.393 & $<0.001$ & & \\
\hline Other DM family history & -0.134 & 1.047 & 0.306 & 0.875 & $0.678-1.130$ \\
\hline Mother DM history & 0.437 & 10.696 & 0.001 & 1.548 & $1.191-2.012$ \\
\hline Father DM history & 0.993 & 51.367 & $<0.001$ & 2.700 & $2.058-3.543$ \\
\hline Both parents DM & 1.045 & 31.220 & $<0.001$ & 2.844 & $1.971-4.104$ \\
\hline Constant & -5.083 & 229.010 & $<0.001$ & 0.006 & \\
\hline $\begin{array}{l}\text { Note: }{ }^{*} \text {,family history of diabetes mellitus was used as dummy variable, and patients without family } \\
\text { history of diabetes mellitus were taken as reference;BMl,body mass index. }\end{array}$ & \multicolumn{5}{c}{} \\
\hline
\end{tabular}

\section{Relationship between drinking history and diagnosed age of T2DM}

In the previous analysis, we found that there was a negative correlation between drinking history and early-onset T2DM. There was no significant difference in the diagnosed age between Father DM history and Both parents DM, and there was no difference between other DM family history and those without family history of DM. We adjusted the classification of family history of DM in the statistical analysis. They were divided into three types. The first type included Father DM and Both parents DM, the second included Mother DM, and the third included other DM family history and those without family history of DM.In this study, 27 women had drinking history.Therefore, we investigated the relationship between drinking history and the diagnosed age of T2DM in male patients, as shown in Table 6. 
Table 6

Comparison of diagnosed age of T2DM with drinking history among male patients

\begin{tabular}{|llllll|}
\hline $\begin{array}{l}\text { Drinking } \\
\text { history }\end{array}$ & & $\begin{array}{l}\text { The first } \\
\text { type }\end{array}$ & The second type & The third type & Whole \\
\hline Yes & N & 121 & 161 & 535 & 819 \\
\hline & $\begin{array}{l}\text { Diagnosed } \\
\text { age }\end{array}$ & $49.5 \pm 10.7$ & $51.8 \pm 10.2$ & $54.1 \pm 11.4$ & $53.0 \pm 10.3$ \\
\hline No & N & 273 & 262 & 934 & 1469 \\
\hline & $\begin{array}{l}\text { Diagnosed } \\
\text { age }\end{array}$ & $45.6 \pm 10.7$ & $49.5 \pm 10.9$ & $53.1 \pm 9.9$ & $51.0 \pm 11.6$ \\
\hline t value & & -3.311 & -2.200 & -1.777 & -4.131 \\
\hline$p$ value & & 0.001 & 0.028 & 0.076 & $<0.001$ \\
\hline
\end{tabular}

\section{Discussion}

T2DM is a complex and multifactorial disease, which is caused by the joint action of genetic factors and environmental factors. Large scale studies on the risk factors of DM in China show that weight gain, waist circumference, dietary pattern, family history of diabetes, hypertension, family history of hypertension and depression are the main risk factors of diabetes ${ }^{[2]}$.Among the newly diagnosed T2DM in the United States, $11.4 \%$ of the patients were under 45 years old ${ }^{[25]}$.In the outpatient survey in Hong Kong, $29 \%$ of patients were diagnosed with type 2 diabetes before the age of $35^{[26]}$. In this study, 2469 $(66.3 \%)$ of the 3725 patients had a family history of diabetes, among which 453 had Father DM history and 696 had Mother DM history, and 190 had both parents DM history.589 cases of early-onset T2DM, accounting for $15.8 \%$.A study in the United Kingdom showed that patients with early-onset T2DM and those late-onset T2DM had a course of $<10$ years, $10-20$ years and $\geq 20$ years. When comparing the blood glucose control and the incidence of cardiovascular disease between the two groups, it was found that patients with early-onset type 2 diabetes had a more serious risk of cardiovascular complications. With the prolongation of the course of disease, the attenuation rate of islet $\beta$ cell function in early-onset T2DM patients was $15 \%$ per year, while that of late-onset patients was $6 \%$ per year ${ }^{[27]}$.To study the clinical characteristics of early-onset type 2 diabetes is of great significance for the mechanism research and prevention of the disease.

The study showed that early onset T2DM patients had a higher proportion of family history of DM (72.8\% vs $65.1 \%, \mathrm{p}<0.05)$, and the $\mathrm{HbA} 1 \mathrm{c}$ was higher at the time of diagnosis $(9.26 \%$ vs $8.63 \%, t=7.413, \mathrm{p}<$ 0.001).Nakanishi et al. followed 960 people without DM for up to 7 years and found that there was a significant increase in the incidence of DM among people with a family history of diabetes ${ }^{[28]}$.Studies have shown that about $84 \%$ of adolescents with T2DM have a family history of $\mathrm{DM}^{[29]}$.Some studies have investigated the population with family history of T2DM in India. It is found that the average age of onset of T2DM in the first generation is 55.95 years old, and that of the second generation is 38.4 years 
$\mathrm{old}^{[30]}$.In order to further compare the correlation between different family history and early-onset diabetes, different from previous studies, we further refined the family history of diabetes according to the incidence of parents. Multiple factor analysis showed that father's and mother's DM family history were related factors of early-onset T2DM. The OR values 2.844(Both parents DM), 2.7(Father DM) and 1.548(Mother DM), respectively.At present, studies have shown that the onset age of T2DM is earlier when the mother's blood glucose is abnormal during pregnancy, which may be related to heredity and intrauterine environment of $\mathrm{DM}^{[31]}$. There are few studies on the influence of paternal diabetes on offspring.Our study suggests that fathers with DM may be more associated with the early onset T2DM in their offspring than mothers with DM.In addition to genetic factors, the familial aggregation of diabetes may also be related to similar living environment. In addition, these families tend to be more vigilant and more aware of diabetes ${ }^{[31]}$.

The proportion of male patients with early-onset T2DM was significantly higher than that of late-onset T2DM patients $\left(70.5 \% \mathrm{vs} 59.7 \%, \chi^{2}=24.106, \mathrm{p}<0.001\right)$ in the present study. The diagnosed age of male was earlier than that of female ( 51.7 vs $54.0, t=-6.283, p<0.001)$. In different family history background, except that both parents have diabetes(46.7vs48.5,t=-1.105,p=0.271), male patients are diagnosed earlier than female patients.In the multivariate logistic regression analysis, it was also found that male sex was significantly correlated with the early onset of T2DM $(O R=2.124, p<0.001)$. More and more attention has been paid to the impact of gender on common chronic diseases ${ }^{[19]}$. Studies outside China ${ }^{[32]}$ and China ${ }^{[20]}$ have reported that there are more males than females with T2DM in adults. Some European epidemiological surveys also show that more men are diagnosed with T2DM at an earlier age, 3-4 years earlier than women ${ }^{[31]}$.In the analysis of the causes, it may be related to social progress, the improvement of automation, the reduction of activities requiring high-intensity physical labor of men, and the level of sex hormone binding globulin and sex hormone ${ }^{[31]}$.Androgen can increase body weight and visceral fat, leading to or aggravating insulin resistance ${ }^{[33]}$.Estrogen is closely related to insulin sensitivity

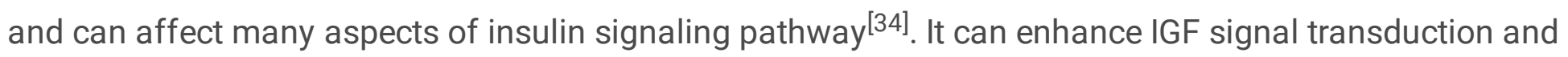
alleviate insulin resistance by inducing the expression of various regulatory molecules of IGF $^{[35]}$. However,a study of 7706 subjects (3896 women) for an average of 13.8 years of follow-up found low testosterone levels predicted high risk of T2DM In men $(H R=2.66,95 \% \mathrm{Cl} 1.91 \sim 3.72, p<0.001)$, while in women this relationship was opposite( $\mathrm{HR} 0.53,95 \% \mathrm{Cl} 0.37 \sim 0.77, \mathrm{p}=0.003)^{[36]}$. It is now becomingly increasingly evident that the functions of the mammalian $\mathrm{Y}$ chromosome are not circumscribed to the induction of male sex ${ }^{[37]}$. While animal studies have shown variations in the $Y$ are strongly accountable for blood pressure (BP), this is yet to be confirmed in humans ${ }^{[38]}$.This is paralleled by studies in man showing $Y$ chromosome haplogroup is a significant predictor for coronary artery disease through influencing pathways of immunity ${ }^{[38]}$. Whether $Y$ chromosome is associated with early-onset T2DM needs further studies.

In this study,drinking history was negatively correlated with the early onset T2DM(OR $=0.682, p=0.002)$. Due to the insufficient sample size of female patients, drinking history and the T2DM diagnosed age were 
further analyzed with different family histories of DM in male patients. The results showed that the age of diabetes diagnosis in patients with drinking history was later in both parents DM and father DM (49.5vs45.6, $\mathrm{t}=-3.311, \mathrm{p}=0.001)$ and mother DM (51.8vs49.5, $\mathrm{t}=-2.2, \mathrm{p}=0.028)$. The difference was not significant in patients with other types of diabetes and those without family history of diabetes mellitus (54.1VS53.1, $t=-1.777, p=0.076$ ). The relationship between alcohol and diabetes is mentioned in different diabetes guidelines that diabetic patients need to prevent hypoglycemia when drinking.By searching PubMed, EMBASE, Cochrane library databases and other databases, some researchers conducted a meta-analysis on a number of studies to assess the relationship between alcohol consumption and the risk of T2DM. It was found that low to moderate alcohol consumption can reduce the risk of diabetes mellitus, and the possible mechanism is that drinking a small to moderate amount of alcohol can improve insulin sensitivity ${ }^{[39]}$.The mechanism needs further study.

\section{Conclusions And Limitations}

In conclusion, patients with early-onset T2DM tend to have more obvious DM family history in China. This survey shows that the parent DM family history especially father diabetes family history, male patients are diagnosed T2DM earlier.Drinking history was negatively correlated with the early-onset T2DM in male patients. We need more aggressive screening for diabetes in children with a family history of diabetes, especially in men.

The findings of this study have to be seen in light of limitations. This study is only a single-center survey, and the research participants are mainly the urban population of Tianjin, all of which are Han residents.In the study, we did not investigate the age of onset of DM of the patients and the blood glucose level of the mother during pregnancy.In this survey, the level of glycosylated hemoglobin was $9.26 \%$ in early-onset T2DM and 8.63\% in late-onset T2DM, which were significantly higher than the normal range (4 6\%), indicating that the diagnosed age may be later than the onset time, and the actual situation of earl-onset T2DM may be more serious. This study is only a cross-sectional study, and its conclusion needs to be further confirmed by prospective multicenter cohort studies.

\section{Declarations}

\section{Acknowledgements}

Zhaohu Hao and Xiao Huang contributed equally and are co-first authors of this article.

\section{Funding}

This work was supported by Tianjin Major Science and Technology Projects(17ZXMFSY00200) and Tianjin Science and Technology Development Strategy Research Projects (18ZLZXZF00740). The 
funding sources had no role in the study design, data collection, analysis and interpretation, and in the writing of the manuscript or in the decision to submit the manuscript for publication.

\section{Availability of data and materials}

All data are available from the corresponding author upon request.

\section{Authors' contributions}

Zhaohu HAO wrote the manuscript. Xiao Huang was responsible for basic information collection and statistical analysis. JunXin Yao was in charge of fundus examination. Xiaohui Liu and Rong Xu were responsible for keeping patients in order and basic information collection and statistical analysis. Feng He proposed the necessity and design of the study. Hailin Shao are in charge of the Metabolic Disease Management Center of Tianjin 4th Central Hospital. All authors read and approved the final manuscript.

\section{Ethics approval and consent to participate}

The IRB of Tianjin 4th Central Hospital approved the collection and use of patients' records according to regulations for clinical trials in humans (IRB approval 2019-SZXLL068). Written informed consent was obtained from each patient.

\section{Consent for publication}

Not applicable.

\section{Competing interests}

The authors declare that there is no conflict of interest.

\section{References}

1. Viner R, White B,D. Christie.Type 2 diabetes in adolescents: a severe phenotype posing major clinical challenges and public health burden[J].Lancet (London, England),2017,389(10085): 2252-2260.

2. R. C. W. Ma.Epidemiology of diabetes and diabetic complications in China[J].Diabetologia,201861(6): 1249-1260.

3. Yeung RO, Zhang Y, Luk A, et al. Metabolic profiles and treatment gaps in young-onset type 2 diabetes in Asia (the JADE programme): a cross-sectional study of a prospective cohort [published 
correction appears in Lancet Diabetes Endocrinol. 2014 Dec;2(12):e17]. Lancet Diabetes Endocrinol. 2014;2(12):935-943.

4. Wang L, Gao P, Zhang M,et al..Prevalence and Ethnic Pattern of Diabetes and Prediabetes in China in 2013[J].JAMA,2017317(24): 2515-2523.

5. Grinstein G, Muzumdar R, Aponte L,et al..Presentation and 5-year follow-up of type 2 diabetes mellitus in African-American and Caribbean-Hispanic adolescents[J].Hormone research,200360(3): 121-126.

6. Gunathilake W, Song S, Sridharan S,et al..Cardiovascular and metabolic risk profiles in young and old patients with type 2 diabetes[J].QJM: monthly journal of the Association of Physicians,2010103(11): 881-884.

7. Pan J,W. Jia.Early-onset diabetes: an epidemic in China[J].Frontiers of medicine,2018,12(6): 624633.

8. Savage PJ, Bennett PH, Senter RG,et al..High prevalence of diabetes in young Pima Indians: evidence of phenotypic variation in a genetically isolated population[J].Diabetes,197928(10): 937-942.

9. Zhou S, Meng X, Wang S,et al..A 3-year follow-up study of $\beta$-cell function in patients with early-onset type 2 diabetes[J].Experimental and therapeutic medicine,201612(2): 1097-1102.

10. Huo L, Magliano DJ, Rancière F, et al. Impact of age at diagnosis and duration of type 2 diabetes on mortality in Australia 1997-2011. Diabetologia. 2018;61(5):1055-63.

11. Færch K, Carstensen B, Almdal TP,et al..Improved survival among patients with complicated type 2 diabetes in Denmark: a prospective study (2002-2010)[J].The Journal of clinical endocrinology and metabolism,201499(4): E642-E646.

12. Al-Saeed AH, Constantino Ml, Molyneaux L, et al. An Inverse Relationship Between Age of Type 2 Diabetes Onset and Complication Risk and Mortality: The Impact of Youth-Onset Type 2 Diabetes. Diabetes Care. 2016;39(5):823-9.

13. Magliano DJ, Sacre JW, Harding JL,et al..Young-onset type 2 diabetes mellitus - implications for morbidity and mortality[J].Nature reviews. Endocrinology,2020,16(6): 321-331.

14. Hillier TA,K. L. Pedula.Complications in young adults with early-onset type 2 diabetes: losing the relative protection of youth[J].Diabetes care,200326(11): 2999-3005.

15. Dabelea D, Stafford JM, Mayer-Davis EJ, et al. Association of Type 1 Diabetes vs Type 2 Diabetes Diagnosed During Childhood and Adolescence With Complications During Teenage Years and Young Adulthood. JAMA. 2017;317(8):825-35.

16. Hao Z, Huang X, Qin Y, et al. Analysis of factors related to diabetic retinopathy in patients with newly diagnosed type 2 diabetes: a cross-sectional study. BMJ Open. 2020;10(2):e032095. Published 2020 Feb 10.

17. Dabelea D, Mayer-Davis EJ, Lamichhane AP,et al..Association of intrauterine exposure to maternal diabetes and obesity with type 2 diabetes in youth: the SEARCH Case-Control Study[J].Diabetes care,200831(7): 1422-1426. 
18. Sattar N. Gender aspects in type 2 diabetes mellitus and cardiometabolic risk. Best Pract Res Clin Endocrinol Metab. 2013;27(4):501-7.

19. Nordström A, Hadrévi J, Olsson T, Franks PW, Nordström P. Higher Prevalence of Type 2 Diabetes in Men Than in Women Is Associated With Differences in Visceral Fat Mass. J Clin Endocrinol Metab. 2016;101(10):3740-6.

20. Yang SH, Dou KF,W. J. Song.Prevalence of diabetes among men and women in China[J].The New England journal of medicine,2010,362(25):2425-2426.

21. Xu Y, Wang L, He J,et al..Prevalence and control of diabetes in Chinese adults[J].JAMA,2013310(9): 948-959.

22. Chen CM, Kong LZ. The guideline for prevention and control of overweight and obesity in Chinese adults[M]. Beijing: People's Medical Publishing House; 2006.

23. World Health Organisation. Guidelines for controlling and monitoring the tobacco epidemic. Genva: Tobacco or Health Programme,WHO; 1997.

24. Huo X, Gao L, Guo L, et al. Risk of non-fatal cardiovascular diseases in early-onset versus late-onset type 2 diabetes in China: a cross-sectional study. Lancet Diabetes Endocrinol. 2016;4(2):115-24.

25. Lammi N, Taskinen O, Moltchanova E,et al..A high incidence of type 1 diabetes and an alarming increase in the incidence of type 2 diabetes among young adults in Finland between 1992 and 1996[J].Diabetologia,200750(7): 1393-1400.

26. Lee SC, Ko GT, Li JK,et al..Factors predicting the age when type 2 diabetes is diagnosed in Hong Kong Chinese subjects[J].Diabetes care,200124(4): 646-649.

27. Song SH,C. A. Hardisty.Early onset type 2 diabetes mellitus: a harbinger for complications in later years-clinical observation from a secondary care cohort[J].QJM: monthly journal of the Association of Physicians,2009,102(11): 799-806.

28. Nakanishi S, Yamane K, Kamei N,et al..Relationship between development of diabetes and family history by gender in Japanese-Americans[J].Diabetes research and clinical practice,200361(2): 109115.

29. Shield JPH, Lynn R,K. C. Wan,et al..Management and 1 year outcome for UK children with type 2 diabetes[J].Archives of disease in childhood,200994(3): 206-209.

30. Panikar VK, Joshi SR, Kakraniya P,et al..Inter-generation comparison of type-2 diabetes in 73 Indian families[J].The Journal of the Association of Physicians of India,2008,56: 601-604.

31. Kautzky-Willer A, Harreiter J,G. Pacini.Sex and Gender Differences in Risk, Pathophysiology and Complications of Type 2 Diabetes Mellitus[J].Endocrine reviews,201637(3): 278-316.

32. Tracey ML, McHugh SM, Buckley CM,et al..The prevalence of Type 2 diabetes and related complications in a nationally representative sample of adults aged 50 and over in the Republic of Ireland[J].Diabetic medicine: a journal of the British Diabetic Association,2016,33(4): 441-445.

33. Elbers JM, Asscheman H, Seidell JC,et al..Long-term testosterone administration increases visceral fat in female to male transsexuals[J].The Journal of clinical endocrinology and 
metabolism,199782(7): 2044-2047.

34. Rettberg JR, Yao J. R. D. Brinton.Estrogen: a master regulator of bioenergetic systems in the brain and body[J]. Front Neuroendocr. 2014;35(1):8-30.

35. Kamble PG, Pereira MJ, Almby K,et al..Estrogen interacts with glucocorticoids in the regulation of lipocalin 2 expression in human adipose tissue. Reciprocal roles of estrogen receptor $a$ and $\beta$ in insulin resistance?[J].Molecular and cellular endocrinology,2019,490: 28-36.

36. Karakas M, Schäfer S, Appelbaum S, et al. Testosterone Levels and Type 2 Diabetes-No Correlation with Age, Differential Predictive Value in Men and Women. Biomolecules. 2018;8(3):76. Published 2018 Aug 20.

37. Turner ME, Ely D, Prokop J,et al..Sry, more than testis determination?[J].American journal of physiology. Regulatory, integrative and comparative physiology,2011,301(3): R561-R571.

38. Khan SI, Andrews KL, Jennings GL,et al..Y Chromosome, Hypertension and Cardiovascular Disease: Is Inflammation the Answer?[J].International journal of molecular sciences,2019;20(12):2892. Published 2019 Jun 13.

39. Li X-H, Yu F-F, Zhou Y-H,et al..Association between alcohol consumption and the risk of incident type 2 diabetes: a systematic review and dose-response meta-analysis[J].The American journal of clinical nutrition,2016103(3): 818-829.

\section{Figures}

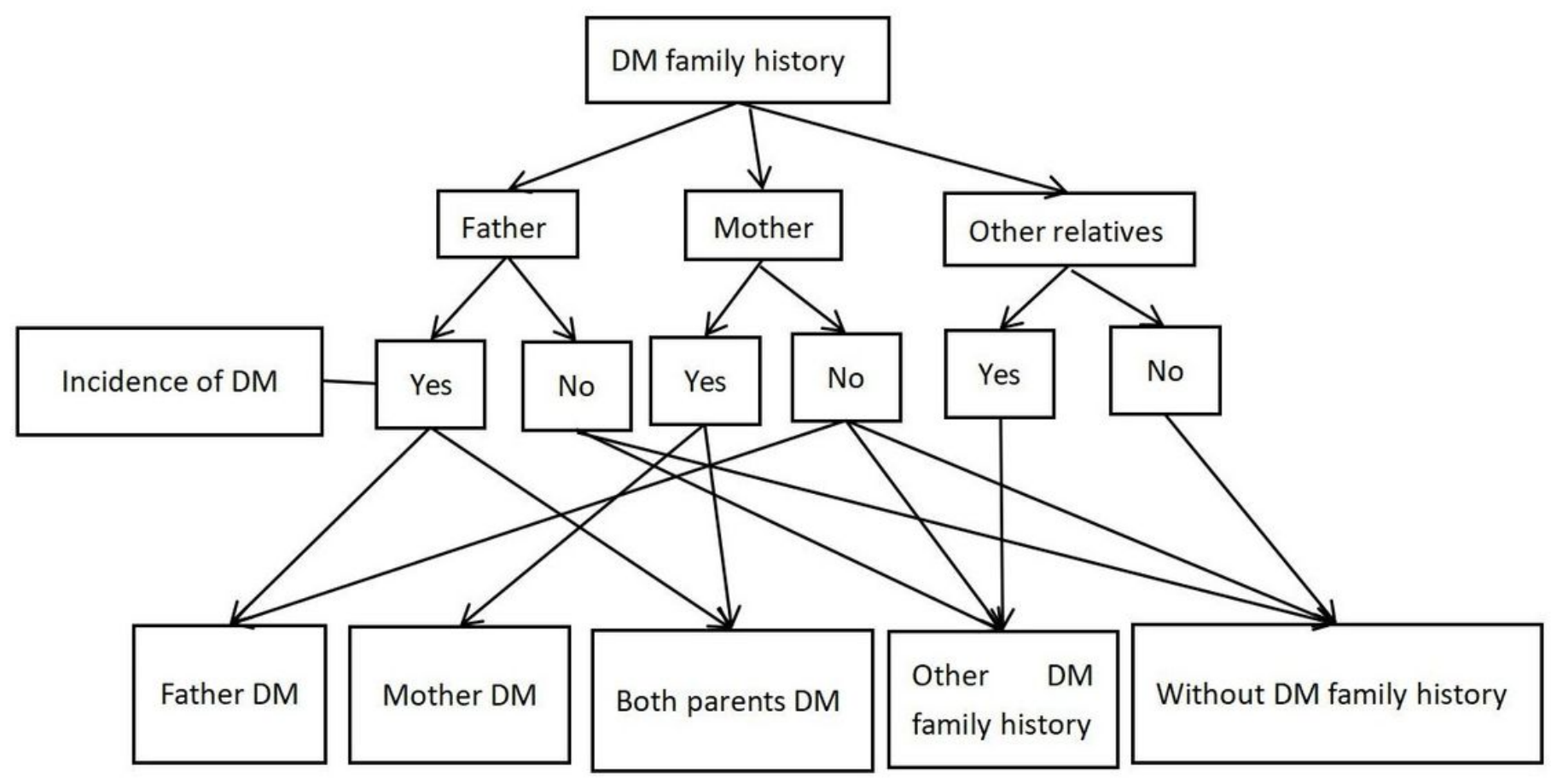

\section{Figure 1}


Classification of family history of DM: In the study,according to the prevalence of diabetes in parents and other relatives, the family history of T2DM can be divided into five types(Figure 1): (a)Father DM:Only the father had diabetes in both parents;(b)Mother DM:Only the mother had diabetes in both parents;(c)Both parents DM,Both parents have DM;(d)other family history of DM (without father or mother with DM) and (e)without family history of DM. Other family histories of diabetes include grandparents, maternal grandparents, siblings and children DM, diabetes Mellitus



\section{Figure 1}

Classification of family history of DM: In the study,according to the prevalence of diabetes in parents and other relatives, the family history of T2DM can be divided into five types(Figure 1): (a)Father DM:Only the father had diabetes in both parents;(b)Mother DM:Only the mother had diabetes in both parents;(c)Both parents $D M, B o t h$ parents have $D M$; (d)other family history of DM (without father or mother with $D M$ ) and (e)without family history of DM. Other family histories of diabetes include grandparents, maternal grandparents, siblings and children DM, diabetes Mellitus 